\title{
Design and Technical Analysis of HVAC Ventilation System in Green Building
}

\author{
Jiawen Zhang ${ }^{1}$ \\ ${ }^{1}$ SHANXI DATONG UNIVERSITY, School of Architectural and Surveying Engineering, Datong, Shanxi, China
}

\begin{abstract}
In recent years, the construction industry has developed rapidly, and there are more and more urban construction projects. The corresponding design requirements for HVAC systems are also getting higher and higher. HVAC has been widely used in all kinds of buildings. While providing convenience for people, environmental pollution has gradually become a topic of concern for people. Therefore, when designing the HVAC system, HVAC not only meets the needs of customers, but also uses green energy saving technology to reduce energy consumption as far as possible. Reduce environmental pollution, so that the HVAC ventilation system of tall buildings can be in a stable and efficient operation state. Improve the operation effect of air conditioning, while reducing energy consumption.
\end{abstract}

\section{Introduction}

HVAC system generally includes three parts: heating, ventilation and air conditioning. It is a technology to control the building's hot and humid environment, indoor air quality and air flow environment, and also includes the control of noise generated by the system itself. In the building HVAC system, the basic is the heating work. The building ventilation system needs to use technical means and HVAC system. The purpose of ventilation is to exchange indoor and outdoor air, keep indoor air fresh and further improve indoor air quality. The heating and ventilation of the building are closely related, and they complement each other. The use of HVAC systems can not only enhance the beauty of buildings, but also improve the air quality. Because it can capture dust above micron and intercept toxic substances in the air, and then protect the health of human living environment.

At present, central air conditioning and household air conditioning dominate the markets, the design of modern air conditioning tends to be more multi-functional. Compared with the previous buildings without HVAC system, the modern HVAC system can adjust the heat load, cold load, wet load and wind load in the building. In urban building planning and design, HVAC is an important part, because in the building HVAC engineering, we should not only be able to control the indoor temperature, but also effectively improve indoor air quality by adjusting the temperature and humidity. Through the effective control of indoor air, humidity, temperature and cleanliness, people maintain the balance of body temperature, and obtain the corresponding comfort.

Architecture not only meets people's basic needs, but also pays attention to the protection of the environment. In recent years, in order to maintain good heating and ventilation demand in buildings, the continuous operation of HVAC system has caused the waste of building energy consumption, environmental pollution and the destruction of energy structure. So, it is necessary to reduce the energy consumption of the system as far as possible, improve the defects of high energy and low efficiency of the previous system, increase the research efforts of HVAC, maximize the use of renewable resources, and promote the joint development of economic and social benefits.

\section{Basic features of architecture}

\subsection{Dense population}

As for buildings that provide human activities, they are usually used in crowded environments such as hospitals and cinemas and have a high service quality. It is because of the density of personnel, the HVAC system requirements in the buildings are higher.

\subsection{Various function}

A variety of functions is one of the main features of the building. Under normal circumstances, buildings need to have multiple functions, and different buildings require different functions. Therefore, this brings some difficulty to the design of HVAC system. Therefore, designers need to design according to the actual use of the building.

\subsection{The poor effect of air conditioning in winter}

Tall and spacious buildings, such as high-rise buildings or office buildings, have poor air conditioning performance in winter. Therefore, in the installation of HVAC ventilation system, designers need to choose 
reasonable air distribution and air outlet, so that HVAC can play the maximum role.

\section{Design principles of HVAC}

\subsection{The principle of saving.}

In the process of building design, the energy conservation and environmental protection of resources are the first priority. In the design of energy saving and emission reduction for building air conditioning, the first step is to make reasonable use of scientific and rational means. Energy-saving design of heating and refrigeration of HVAC, coupled with the implementation of green construction technology to achieve the purpose of energy saving and emission reduction. This can not only reduce energy consumption, but also ensure that the use of HVAC does not burden the environment, at the same time, the construction cost can be reduced, and the cost can be managed and controlled scientifically and reasonably, so as to realize the design of green and energy-saving air conditioning system. In the design process, designers need to analyze and calculate the air-conditioning system in the period of maximum energy consumption throughout the year, so as to ensure that the air-conditioning system can adjust its functions more reasonably during operation and effectively improve its energy saving role.

\subsection{Principle of adaptability}

In terms of HVAC, the relevant personnel should pay attention to the impact of the specific environment on the building HVAC system in the design process. The air conditioning system of a building is used in different environments, or the resource utilization is different, which may cause the performance difference of the air conditioning system. The selection of heating equipment should be closely combined with the local climate and geographical environment to make the optimal plan. The purpose of this adaptive principle is to ensure that the application of green technology is consistent with the existing HVAC system, and to avoid the impact of the application of new technology on the coordination of the original building. Therefore, the personnel needs to adhere concept of green operation of the HVAC system in different environments, adapting to the original design methods, and making progress and development of the HVAC system.

\subsection{Comfort principle}

Comfort is mainly for the feelings of the people in the building, mainly for the purpose of the HVAC system in the heating and air supply, to provide a comfortable and efficient environment for the indoor persons. Through the HVAC system, air conditioning should not only play the role of regulating temperature, but also adjust the indoor air quality and humidity, keep the indoor air fresh and indoor personnel feel comfortable.

\section{Technical points of HVAC ventilation system}

\subsection{Use energy-saving technology}

With the continuous development of social economy and productivity, the consumption of energy resources is also increasing, and exhausting emissions pollution to the environment, environmental protection is imminent. Therefore, the application of energy-saving technology must be strengthened. And in the design process, we can use the waste heat cycling technology, the heat transfer in the circulation system to transfer the residual heat from one part to the other. This technology can meet the needs of indoor persons better. Natural cold source can also be used. According to the load characteristics of the building and the local climate conditions, natural cold source should be skillfully used to provide free heat source for the area in the building that uses cold all the year round. The use of energy efficient technology can effectively use natural resources, improve the overall energy efficiency, thus reducing the energy consumption of the building.

\subsection{Fresh air system technology}

Fresh air system design is to filter, cool or heat the indoor air, then deliver into the air-conditioned room according to the stipulated new air volume standard. Different building types require different amounts of fresh air. In order to save energy, circulating air is widely used in the design of air conditioning system. If there is less fresh air or fresh air in the air-conditioned room, the indoor air quality will decline and people will feel uncomfortable. In addition, in the design of ventilation system, professionals should also pay attention to the design of natural ventilation. For buildings, high quality external air environment can effectively improve indoor air quality. Natural ventilation and air-conditioned air supply effectively combine. Appropriate natural ventilation can effectively reduce the use of electric power equipment with consuming energy. From the current effect of people's use, natural ventilation doesn't consume energy, saves resource better and more healthy at the same time, which is beneficial to residents' happiness.

\subsection{Use heat recovery technology}

Analyzed from a broad perspective, the essence of heat recovery is to recycle and reuse the heat formed in the operation of the chiller in a timely manner in order to provide heat to users. Using heat recovery technology, it can be found that in the process of heat recovery application of high temperature and high pressure refrigerant, water can be directly transported to the heat recovery device through circulating water pump, and then heat exchange can be realized through water and high temperature refrigerant steam. The refrigerant can raise the water temperature through condensation reaction. Then it will be returned to the storage box, the water pump will be directly transported to the storage 
box to realize the recycling heating treatment, so as to achieve the rise of water temperature. Heat recovery technology works by transferring excess heat from one part of the system to another through heat transfer in the circulatory system Heat recovery technology can not only save energy, but also reduce energy consumption, which is very helpful to reduce air pollution. Heat recovery technology can promote the air circulation of buildings with large spaces, which can effectively improve the efficiency of energy use. Relevant staff can make some adjustments to the heat recovery technology according to local conditions.

\subsection{Use Ground-Source Heat Pump technology}

The ground system links the heat pump to the underground and allows for extraction of heat from the ground or injunction of heat into ground. This kind of air conditioning system can effectively improve the use efficiency of thermal energy resources in the front layer field, and make HVAC play a greater role, so as to truly realize the effect of heating the building in winter and the function of cooling in summer The low heat absorbed by the heat pump from low heat energy reduces the consumption of high grade energy in quantity. Because the ground energy temperature is stable, so the heat pump unit can be more safe in the process of operation. Taking heat pump as the cold and heat source of air conditioning system, low temperature waste heat in nature can be transformed into regenerative heat energy available in HVAC system. In the cold winter, geothermal energy can be used to bring heat from underground to the ground, where it can be converted to heat for buildings. In summer, the heat from the ground can be stored underground to cool the building. At the same time, heat pump technology is used to reduce environmental pollution and provide more water for residents.

\subsection{Frequency conversion and energy saving technology}

When the load of HVAC in the building changes significantly, the frequency of the HVAC system can be adjusted by the fan, water pump and water chiller, improving the operating rate of equipment, promoting the HVAC system in the process of operation to achieve energy saving standards and strengthen the use of resources. Through frequency conversion technology, the energy saving effect of HVAC can reach more than $30 \%$, and after the use of frequency conversion technology, the frequency conversion system and variable air device in HVAC constitute variable air volume system This system increases the comfort of the building's residents and reduces HVAC energy consumption. By using the frequency conversion, on the one hand, HVAC in all rooms throughout the building will not constrain or restrict each other, helping building residents to get more comfortable experience , on the other hand, the cold and heat sources can be kept at a stable frequency to protect the water pump in HVAC and reduce the consumption of cold and heat energy.

\subsection{Solar energy technology}

Solar energy is a common and widely used energy saving technology. Solar energy is inexhaustible, and its cleanliness is high, zero pollution, so it is widely used in all walks of life. The principle of solar energy technology is to convert light energy into heat energy, and the combination of HVAC and solar energy technology is a major innovation in HVAC design. In the green city and the design of HVAC can also give full play to the solar energy saving technology, can realize the conversion of solar energy to heat energy through intelligent circulation and collector control system. Rational use of solar energy technology in building engineering HVAC can fundamentally increase the energy saving effect. This technology can also increase energy utilization rate and reduce energy consumption. At the same time, it can bring economic and environmental benefits, help urban construction and development save more energy.

\section{Building heating and ventilation and air conditioning installation points}

\subsection{Strictly control the production of air ducts and reasonably arrange pipelines}

In the heating and ventilation and air conditioning installation process, the production of air duct and pipeline layout is the basic, in the whole project can have a greater impact. Before the production of the air duct, the design drawings need to be strictly reviewed, and the problems arising in the production can be solved in time. In addition, the layout of the pipeline should be as scientific and reasonable as possible, as far as possible to avoid the pipeline cross, to ensure that the pipeline layout is reasonable.

\subsection{Reasonable selection of materials}

Building construction materials to a certain extent affect the air conditioning installation system, at the same time the selection of materials will also affect the system installation. Making a good investigation before purchasing, trying to choose high efficiency and energy saving materials, to ensure that the production materials meet the installation and debugging standards. And the materials are need to be tested before the use, and then they can be put into construction use. The construction of a system of supervision and management system, and the application in practice, require designers to pay attention to the installation design form, pay attention to details, to ensure that the details of the connection is accurate, in line with the overall requirements of construction.

\section{3. commissioning and operation after installation}

Heating, ventilation and air conditioning systems need to be debugged after installation. In the process of trial operation, exclude the influence of external environment, 
check whether there are some other problems in the air conditioning system. If other problems are found in the process of trial operation, it is necessary to contact the design unit and the construction unit for consultation, and develop a reasonable solution. After the trial operation, the heating, ventilation and air conditioning system can be formally put into use.

\section{The significance of new technology}

New technology has a direct relationship between the design quality and comfort of HVAC. While providing comfort for human activities, it also accelerates the pace of environmental protection New HVAC technology has brought a great impact on our lives, and has played a significant role in environmental protection, energy conservation and emission reduction. The technology can not only improve the operation effect of air conditioning, reduce energy consumption, but also meet people's living needs. As a designer of HVAC, it is necessary to master the basic principles and knowledge of HVAC design, master the key technologies of green building energy saving, and implement the concept of green environmental protection. Strengthen the application of new HVAC technology in the design of ventilation and air conditioning system, so as to play the role of HVAC ventilation system and promote the continuous development of HVAC system engineering.

\section{Conclusions}

To sum up, with the improvement of international strength, people's quality of life has also risen to a higher level, and HVAC energy saving design is the internal need for the development of green buildings. It can reduce the energy consumption of air conditioning system, and can improve the indoor temperature and humidity and ventilation environment with the support of a variety of technologies. Only when people fully realize the necessity of energy saving design of HVAC system, and adhere to the local conditions, energy saving and environmental protection and the maximum utilization of resources, systematic use of air conditioning energy saving design methods, effectively improve the level of energy saving design of HVAC and improve the indoor environment quality, promote the healthy and orderly development of green buildings.

\section{References}

1. Lei, Y.P. (2011) Natural Ventilation Potential Analysis of Rural Residential Building in China. In: International Conference on Electric Information and Control Engineer. Wuhan, China. pp. 4292-4297

2. Zhou, Q. (2011) Strategies for Natural Ventilation of Residential. In: International Conference on Electric Information and Control Engineering. Wuhan, China. pp. 6134-6136

3. Xiang, L. P. (2014). Research on air distribution of displacement ventilation system in large workshop.
In: Workshop on Advanced Research and Technology in Industry Applications. Ottawa, Canada. pp. 39-42.

4. Zhu, S.T. (2011) Architectural design on natural ventilation. In: International Conference on Multimedia Technology. Hangzhou, China. pp. 6256-6259.

5. Yu, W.; Li, N.; Zhang, W.; Qian, F. (2011) Case study on sustainable building design. In: International Conference on Electric Technology and Civil Engineering. Lushan, China. pp. 2984-2987.

6. Cui, H.; Li, G.B.(2018) Design and Implementation of Intelligent Building Engineering Information Management System. In: International Conference on Virtual Reality and Intelligent Systems. Changsha. pp. 481-484.

7. Haw, L. C; Saadation, O.; Baharuddin, A.H.; Mat, S.; Sulaiman, M.Y.; Sopian, K.(2012) Case study of wind -induced natural ventilation tower in hot and humid climatic conditions. In: Business Engineering and Industrial Applications Colloquium. Kuala Lumpur, Malaysia. pp. 178-183.

8. He Y.H.; Huang, H. C.; Lin, F.(2011) Fuzzy control applied to the bath room ventilation system. In: International Conference on Machine Learning and Cybernetics. Guilin, China. pp. 1243-1249.

9. Domenico, C.; Francesco, M.; Daniele, M.(2018) Energy Saving Optimizing the Ventilation Control in a Big Shopping Center. In; International Conference on Environment and Electrial Engineering and Commercial Power Systems Europe.Palero. pp. 1-6. 